\title{
ANA MARÍA CARO MALLÉN DE TORRES: UNA ESCLAVA EN LOS CORRALES DE COMEDIAS DEL SIGLO XVII
}

\author{
JUANA ESCABIAS \\ Escuela de Arte Dramático del Ayuntamiento de Madrid \\ escabiasjuana@gmail.com
}

\section{RESUMEN}

Este artículo reconstruye la biografía de la dramaturga andaluza del Siglo de Oro Ana Caro Mallén, aportando informaciones desconocidas hasta ahora como su lugar y fecha de nacimiento y fallecimiento, su nombre completo y su primer y segundo apellido y referencias documentales inéditas sobre su entorno familiar, personal y literario. Los datos más sorprendentes de esta biografía son que la autora nació en Granada, bajo la condición de esclava.

Palabras Clave: Caro Mallén, teatro Siglo Oro, dramaturga española.

\section{Abstract}

This article reconstructs the biography of the playwright Andalusian Golden Age Ana Caro Mallen, providing previously unknown information as place and date of birth and death, your full name and your first and last name and unpublished documentary references about their family, personal and literary. The most striking of this biography is that the author was born in Granada, under the condition of a slave.

KEY wORDS: Caro Mallen, Golden Century Theatre, Spanish playwright. 
Muchos han sido los investigadores españoles y extranjeros interesados en la obra de Ana Caro Mallén sorprendidos por la ausencia de datos biográficos sobre esta importante dramaturga andaluza del Siglo de Oro. Ya en el siglo XIX, José Sánchez Arjona se refería a esa situación realizando el siguiente comentario: «De lamentar es la falta de noticias biográficas de quien llegó a obtener señalado lugar entre los escritores de su época. Si escasas son las noticias de su vida, no lo son menos las de su obra. De las muchas comedias que dicen escribió solo se conservan dos.» (Sánchez Arjona, 1889: 349)

A José Sánchez Arjona le debemos importantes informaciones sobre la trayectoria artística de la autora. Él fue quien mencionó por primera vez varios autos sacramentales escritos por ella y representados durante diferentes ediciones de las Fiestas del Corpus en la Sevilla del siglo XVII, de los que aseguraba había quedado constancia por varias actas de pago del Ayuntamiento de Sevilla. Un siglo después, siguiendo las pistas de Sánchez Arjona, el francés Jean Sentaurens halló esos documentos. (Sentaurens, 1984: 1119 y 1149) Otro documento de pago fue encontrado en el Archivo Histórico del Ayuntamiento de Madrid por Cristóbal Pérez Pastor, en esta ocasión la autora era remunerada por elaborar la crónica de un festejo real. (Pérez Pastor, 1910: 97)

Las reediciones e investigaciones en torno a Ana Caro Mallén no han cesado desde el siglo XvII, cuando ella desarrolló su carrera en Sevilla. La localización completa de su producción bibliográfica (diseminada por bibliotecas de diversos países) experimentó un gran avance durante las últimas décadas del siglo Xx. A finales de mil novecientos ochenta, la filóloga sevillana Lola Luna encontró en la Biblioteca Colombina su auto sacramental Coloquio entre dos, que apareció en forma manuscrita en un códice de obras de diferentes autores. La existencia de este texto se conocía por los documentos de pago mencionados por Sánchez Arjona y Sentaurens. La pieza fue representada en Sevilla durante las Fiestas del Corpus de 1645, la autora cobró por ella 300 reales. Con este hallazgo como epicentro, Lola Luna elaboró un posterior trabajo en el que a través de los testimonios de autores contemporáneos a Ana Caro Mallén ofrecía datos sobre el paso de la autora por algunas academias de letras sevillanas y de su único y fugaz viaje de trabajo a Madrid, intentando recomponer un círculo de amistades alrededor de ella. A pesar de los logros de su investigación, ella misma reconocía la falta de informaciones biográficas fundamentales:

¿Dónde buscar huellas de la existencia de una mujer como Ana Caro Mallén, con acceso a los circuitos de impresión, distribución, representación y remuneración, en un mundo en el que cientos de dramaturgos competían entre sí por mercantilizar su escritura intentando imitar aún en la lejanía a Lope de Vega o Tirso de Molina?, una autora que parece acercarse a esa quizás hipotética «generación de 1635». (Luna, 1993: 11)

Coincidiendo con las apreciaciones de Sánchez Arjona y Lola Luna, otros especialistas han destacado el enigma biográfico que envolvía a Ana Caro Mallén, fundamentalmente los norteamericanos, entre los que la dramaturga andaluza goza de más atención crítica que en nuestro país. Matthew Stroud (Stroud, 1986), Teresa Soufas (Soufas, 1991) y Luisa Foley (Foley, 1977) son algunos de ellos. Esta última investigadora llegó a afirmar que la biografía de «Ana Caro» estaba sometida a un misterio. María José Delgado, profesora universitaria en EEUU de origen español y con varios trabajos en su haber sobre la dramaturga andaluza, asegura que, conocedores de la falta de información biográfica so- 
bre el personaje, «los investigadores norteamericanos se abstienen en ese terreno y pasan directamente al análisis textual». (Delgado, 1993: 13)

Una ardua investigación nos ha permitido recomponer los datos biográficos básicos de Ana Caro Mallén. El trabajo ha supuesto años de esfuerzo e indagación por diferentes archivos y fondos documentales de los siglos XVI y XVII, buscando el rastro de lo que para todos (nosotros inclusive) era un enigma. Los resultados de esa búsqueda se presentan a continuación.

\section{CONSIDERACIONES SOBRE UN APELLIDO}

Durante años se ha hablado de Ana Caro Mallén como si bajo esa denominación estuvieran incluidos su nombre y el primero y segundo de sus apellidos. De hecho, muchas de las ediciones de sus obras realizadas tras el fallecimiento de la autora (la práctica totalidad de las ediciones contemporáneas) aparecen firmadas exclusivamente a nombre de Ana Caro. Pero Caro Mallén (o Caro de Mallén) es un apellido compuesto. El nombre completo de la escritora fue Ana María Caro Mallén de Torres. Sus padres fueron Gabriel Caro de Mallén y Ana María de Torres. No eran padres biológicos, sino adoptivos. Gabriel era sevillano, nacido en Lora del Río aunque afincado en Granada, ciudad de la que era originaria su esposa y donde también nació la niña que con el tiempo sería afamada escritora representada en los corrales de comedias de la época, y aceptada en los más reputados salones literarios y en la corte de los Austrias.

También resulta frecuente emplear el apellido «de Soto» acompañando a esta dramaturga, sin que haya una sola fuente documental que certifique la validez de esa práctica. La primera ocasión en que aparece ese apellido vinculado a Ana Caro Mallén es en una copia manuscrita de su comedia El conde Partinuplés custodiada en la Biblioteca Nacional de España, sin lugar ni año de edición y fechada en el catálogo como «del siglo XVIII». En la hoja preliminar se dice: «Doña Ana Caro Mallén de Soto / El Conde Partinuples». En la primera hoja se dice: «La gran comedia de / el conde partinuples / de Doña Ana Caro natural / del reino de Andaluzia» ${ }^{1}$. El mencionado manuscrito, de 42 hojas formato $4^{\circ}$ y procedente de los fondos de la Biblioteca de Osuna, no es el primer testimonio de esta comedia; le preceden una copia manuscrita del siglo XVII, una edición de 1653 realizada por Diego Balbuena en Madrid y otra edición sin fecha, lugar ni nombre del editor datada en la segunda mitad del siglo XVII. En todos ellos, la autora aparece nombrada exclusivamente como Ana Caro Mallén (o Caro de Mallén). Las informaciones testimoniales que poseemos sobre ella, realizadas por quienes la conocieron en vida (elogios de otros autores, inclusión de su nombre en textos ajenos o antologías, etc...) nunca utilizan el apellido «de Soto». Lo mismo ocurre en las fuentes documentales que han llegado hasta nosotros a propósito de ella (documentos de pago por sus obras, solicitudes de cobro, etc. $)^{2}$.

\footnotetext{
1 BNE. Signatura: MSS 16.755. Microficha 2467.

2 Hasta la fecha de hoy, se conocía la existencia de cuatro documentos, tres del Archivo Municipal de Sevilla (Pago efectuado en 1641. Sección 15. Manuales de Mayor. Tomo 30. Asiento 37/46, 19 de junio de 1641. Folio 76v. Signatura: H/3205. // Pago efectuado en 1642. Sección 2. Carpeta 18. Documento número 46, de julio de 1642. Signatura: H/672. // Pago efectuado en 1645. Sección 2. Carpeta 20 (2). Documento número 113, de 29 de mayo de 1645. Signatura: H/674.) y uno del Archivo Histórico del Ayuntamiento de Madrid (Signatura: 3-687-4).
} 
Manuel Serrano y Sanz, que merece un reconocimiento destacado en la Historia de la Literatura Española por sus esfuerzos a favor de la revalorización de las escritoras españolas y su obra, habla de «Ana Caro Mallén de Soto» en su extraordinario manual Apuntes para una Biblioteca de Escritoras Españolas desde el año 1401 al 1833, que a nuestro juicio todavía constituye una referencia internacional (Serrano y Sanz, 1903: 177). La vida está llena de paradojas, y una de ellas es que don Manuel, en el apartado de su manual dedicado a esta escritora, reproduce un fragmento del testamento de Juan Caro Mallén (su hermano) en el que el moribundo menciona a su primo, Francisco de Torres Castejón: «Y assí mismo se ajusten las quentas que tengo con don Francisco de Torres Castejón, mi primo, caballero de la Orden de Santiago, y se satisfaga de una parte á otra lo que se deuiere» ${ }^{3}$.

Reiteramos nuestro reconocimiento a la figura y labor de don Manuel Serrano y Sanz. Gracias a él y a «sus consejos» pudimos encontrar la pista de esta escritora. Porque fue don Manuel Serrano y Sanz, a finales del 1800, el primero que se atrevió a sostener que los orígenes de Ana Caro Mallén estaban en Granada, y no en Sevilla (como entonces aseguraba todo el mundo y hasta hoy se ha venido aseverando mayoritariamente a pesar de que nadie hubiera podido demostrar la hipotética cuna hispalense de la escritora). Serrano y Sanz no aportaba documentos que sostuvieran su afirmación, aunque hablaba con la seguridad de quien los había conocido y poseído; se limitaba a defender con rotundidad que fue hermana de don Juan Caro Mallén, natural de Granada. A favor de la solvencia de este investigador podríamos aportar cientos de pruebas, entre ellas que resolvió un error generado con otra escritora barroca, Mariana de Carvajal y Saavedra, de la que tradicionalmente se afirmaba que nació en Granada. Serrano y Sanz comprobó que había nacido en Jaén gracias a un documento que encontró en el Archivo Histórico Nacional referente al acto protocolario en el que el hijo de la escritora (Don Rodrigo Velázquez de Carvajal) recibió el hábito de la orden de Santiago. Con Leonor de la Cueva y Silva, de la que durante años se afirmó que era hija del también escritor Francisco de la Cueva, de nuevo don Manuel resolvió el error de bulto, aportando un poema de la autora de 1625 (su primera composición poética) dedicada a «su tío» Francisco de la Cueva. Respecto a María de Zayas, don Manuel determinó la imposibilidad de que pertenecieran a ella dos diferentes partidas de defunción presentadas por terceros como de la escritora.

Nuestra investigación en busca de los orígenes de Ana Caro Mallén se inició y desarrolló en Sevilla pero, paralelamente y por respeto a la opinión de don Manuel Serrano y Sanz, se abrió otro frente en Granada. Y fue en esa última ciudad donde aparecieron las primeras pistas sobre los Caro Mallén.

\section{El apellido Caro Mallén en la Historia de España}

Según el Instituto Nacional de Estadística de España, el apellido compuesto Caro Mallén no existe en la actualidad en nuestro país. Hay 20.705 españoles cuyo primer apellido es Caro y 20.501 que lo poseen como segundo apellido. El apellido Mallén es menos

3 Testamento de don Juan Caro de Mallén. Archivo de Protocolos de Madrid. Protocolo de Jerónimo de la Flor, año 1655, folio 480r. 
frecuente; 1.742 españoles lo llevan como primer apellido y 1.602 en segundo lugar ${ }^{4}$. El apellido Caro Mallén tampoco aparece mencionado por los expertos en genealogía ni en los manuales de heráldica. Ni Rafael Sánchez Saus, (Sánchez Saus, 1991), ni Adolfo de Salazar Mir (Salazar Mir, 1995-1996) ni Baltasar Cuartero Huerta y Marqués de Siete Iglesias (Cuartero Huerta, 1957-1970) ni Alberto y Arturo García Carraffa (García Carraffa, 1952-1968) ni el resto de especialistas en linajes españoles lo incluyen en sus tratados. Sí aparecen en esos tratados los apellidos Caro y Mallén estudiados de forma individualizada. Ambos poseen un origen noble. Los Caro llegaron a Andalucía con el rey Fernando III durante la Reconquista, siendo casi los primeros en poblar la villa de Utrera entre los siglos XII y XIII ${ }^{5}$. El apellido Mallén tiene su origen en la localidad aragonesa del mismo nombre.

El apellido Caro de Mallén, actualmente extinguido, tuvo aproximadamente siglo y medio o dos siglos de vida. Debido a su corta existencia, no es posible encontrarlo en los tratados heráldicos. La primera constancia que tenemos de él se produce a mediados del siglo XVI (en 1550), y la última a finales del siglo XVII (en 1683). El apellido nace en la localidad sevillana de Lora del Río, conformada a principios del siglo XIII tras ser el territorio conquistado a los árabes. José González Carballo, cronista de la ciudad y autor de diversos tratados históricos sobre la que en su día fue una importante Villa de la que dependían otras localidades, vincula el origen del apellido Caro de Mallén a la unión por la vía del matrimonio de dos vástagos de estas dos familias, que pertenecían a la oligarquía local y ostentaban el poder en ella a través de sus cargos de regidores. «En Lora del Río los cargos de regidores eran perpetuos y hereditarios. Se disponía de la propiedad de ese oficio, que incluso podía venderse a terceros» (González Carballo, 1987: 19) $)^{6}$.

La fusión del apellido pudo producirse antes de 1520, cuando encontramos a Bartolomé Caro y Hernando de Mallén ostentando al mismo tiempo el cargo de regidor en la villa de Lora del Río. Hernando ya figura como regidor en las Actas Capitulares de 1516, dirimiendo un pleito contra los vecinos. En las Actas Capitulares del 15 de mayo de 1541, aparece una reunión del concejo para aceptar que se establezcan ordenanzas de vecindad con una villa de Córdoba (Peñaflor). Entre los componentes de ese concejo, se encuentra ya Hernando Caro de Mallén (seguramente descendiente de los anteriores). Hernando Caro de Mallén reaparece en 1575, también actuando como regidor de la villa. (González Carballo, 1987: 59) En 1683, trascurrido más de un siglo desde la primera mención del apellido, ostenta el cargo de regidor Francisco Caro de Mallén (González Carballo, 1987: 73)

El rastro de esta familia reaparece durante años en Lora del Río y en diferentes enclaves de Sevilla y provincias limítrofes, siempre vinculado al ejercicio del poder, incluso en muchos casos administrando justicia. En la Real Chancillería de Granada, se encuentran

\footnotetext{
4 Fuente: Instituto Nacional de Estadística de España. Datos de la explotación estadística del Padrón de Habitantes. INE: 2012.

5 Enciclopedia heráldica y genealógica hispano-americana, Madrid, Imprenta de San Antonio Marzo, 1926, vol. 23, pp. 222-232.

6 Estas informaciones aparecen en las publicaciones de González Carballo y en las Actas Capitulares de Lora del Río (Sevilla), custodiadas en su Biblioteca Municipal, fechas de 1510 a 1690.
} 
diferentes documentos en ese sentido ${ }^{7}$. De forma paulatina y arbitraria, unos y otros descendientes desgajan el apellido y comienzan a firmar exclusivamente como Caro o como Mallén. Así, el apellido compuesto Caro Mallén/Caro de Mallén va desapareciendo hasta que queda extinguido por completo. En la rama familiar directamente vinculada con Ana María Caro de Mallén de Torres (padres y dos hermanos), sus miembros dejaron que el apellido se perdiera antes de comenzar el siglo XvIII. Ana María no se caso ni tuvo descendencia, su hermano menor fue fraile dominico y el mayor solamente tuvo un hijo, llamado Sancho, que mantuvo el apellido; pero su hijo, Luis Antonio, lo fragmentó, dejando que se perdiera la segunda parte. En el testamento de Juan Caro de Mallén, fechado en 1655, ya consta esa evidencia:

Iten mando y es mi voluntad que á la dicha doña Luysa de Auila mi mujer no se le pidan quentas ningunas de nada, mas de las que quisiere dar; asi por don Sancho Caro de Mallén, mi hijo, como por ninguna persona, porque estoy muy satisfecho de su bondad. (...)

Iten mando á don Luis Antonio Caro de Aguilera mi nieto, hijo de mi dicho hijo... ${ }^{8}$

Los Caro de Mallén, una familia en sintonía con el espíritu del Siglo de Oro

Sabemos que el padre adoptivo de Ana María Caro de Mallén, Gabriel, nació en Lora del Río en 1569 porque su expediente matrimonial ha sido hallado en los archivos del Real Arzobispado de Granada. Gabriel Caro de Mallén se casa en Granada, en junio de 1596, con Ana María de Torres. El permiso para la celebración del enlace está fechado el 10 de junio. Él tenía 27 años y era procurador de la Real Audiencia de Granada, la novia tenía 21 años. Gabriel pertenecía como feligrés a la Iglesia Mayor (hoy SagrarioCatedral) y Ana María a la parroquia de La Magdalena, en la que había nacido. En ese expediente se recoge que hacía diez años que Gabriel vivía en Granada, deduciéndose por sus palabras que se había trasladado allí junto a sus padres.

Gabriel Caro de Mallén, procurador de esta Real Audiencia. (...) Hijo de Fernando de Mallén, regidor que fue de la villa de Lora y de Catalina Fernández de Vargas, su mujer. Natural de la dicha villa de Lora y vecino de esta ciudad de más de diez años a esta parte en la parroquia de la Iglesia Mayor. (...) Y es de edad de más de veintisiete años, mozo soltero y por casar, libre para poder contraer matrimonio y no ha hecho voto de castidad ni religión ni ha dado palabra de casamiento a ninguna mujer. (...)

Ana María de Torres, vecina de Granada, hija del jurado Juan Rodríguez y doña Catalina de Aguilar. (...) De edad de 21 años y no ha hecho voto de castidad ni de religión ni ha dado palabra de casamiento a ninguna persona, y se quiere casar con Gabriel Caro de Mallén, que no es su pariente en ningún grado?.

7 Real Chancillería de Granada: signatura 9630, pieza 18; signatura 9691, pieza 14; signatura 10.048, pieza 5; signatura 2862, pieza 11; signatura 10.148, pieza 17; signatura 10.183 , pieza 39 .

8 Testamento de don Juan Caro de Mallén. Archivo de Protolocos de Madrid. Protocolo de Jerónimo de la Flor, año 1655 , folios 479r/v y 480r/v.

9 Expediente matrimonial de D. Gabriel Caro de Mallén y Da Ana María de Torres. Archivo Histórico del Arzobispado de Granada. Legajo 14. Pieza n 97. 
Trabajar en la Real Chancillería y Audiencia de Granada significaba estar directamente vinculado a la Corona. El propio monarca otorgaba los «recibimientos» (títulos de posesión del oficio). El organismo fue trasladado desde Ciudad Real a Granada en 1505, por una promesa de los Reyes Católicos, que deseaban engrandecer el territorio dotándolo de este poderosísimo tribunal de justicia espejo y ejemplo de toda la hispanidad. Solo Valladolid poseía otra Chancillería, y sus proporciones y dotaciones eran menores. Henríquez de la Jorquera describe la magnificencia de la institución granadina, que poseía presidente, gobernador, diez y seis oidores, cuatro alcaldes de corte y tres de hijosdalgo, dos fiscales... «y su número de procuradores es grande» (Henríquez de La Jorquera, 1934: 73) El mismo autor hace hincapié en la importancia del apellido de Torres (el de la novia) en Granada, cuando menciona al granadino Francisco de Torres, que fue capitán de los estados de Flandes, y a su hermano Baltasar de Torres (caballero veinte y cuatro de Granada). Pertenecer al grupo de «los veinte y cuatro» era una distinción en la Granada de la época, distinción que podía heredarse o venderse (Henríquez de La Jorquera, 1934, 665)

Gabriel Caro de Mallén se trasladó desde Lora del Río a Granada porque tenía familiares dentro de la propia Audiencia, que le ayudaron a conseguir una plaza en la institución. En el capítulo preliminar de las Ordenanzas de la Real Audiencia y Chancillería de Granada, se menciona a un reducido y selecto grupo de personalidades reunidas para crear la normativa que en el futuro regiría su funcionamiento.

En la ciudad de Granada, a feys días del mes de Noviembre de mil y seiscientos años, tomando un acuerdo para que se establezcan unas ordenanzas... (...) el licenciado Pedro Mallén, Oydor de la Dicha Audiencia... Ordenanzas de la Real Audiencia y Chancillería de Granada. (MENA, 1601, 2)

En 1625, Henríquez de la Jorquera recoge en sus crónicas el fallecimiento de este personaje, el licenciado Mallén, que pertenecía al consejo de su majestad.

Los testigos que participaron en el enlace matrimonial de Gabriel Caro de Mallén y Ana María de Torres fueron Francisco Carrillo de Figueroa, Alonso Díaz de Palencia y Francisco de León, también procurador de la Real Chancillería y Audiencia de Granada. Durante más de tres años la pareja no tuvo hijos. O tenían dificultades para procrear o perdieron a algún bebé a punto de nacer o recién nacido. Este extremo no ha podido ser comprobado porque que el Libro 1 de Defunciones de la Parroquia de Sagrario Catedral (de 1560 a 1605), a la que pertenecía el matrimonio, desapareció siglos atrás. El matrimonio compuesto por Gabriel Caro de Mallén y Ana María de Torres bautizó a su primer hijo el 7 de marzo de 1600. «Juan, hijo de Gabriel Mallén», aparece registrado en el índice del libro de bautismos $\mathrm{n}^{\circ} 7$ de la parroquia de Sagrario-Catedral (de 1600 a 1610). La inscripción completa del bautismo está en la página 7.

En siete de marzo de mil y seyscientos años bautiza Gabriel a Juan, hijo de Gabriel Mallén y de su mujer doña Ana de Torres. Fue padrino el jurado Pedro de Balenzuela, testigos Gabriel de Machuca y Juan Sillero ${ }^{10}$.

10 Archivo parroquial de la iglesia de Sagrario-Catedral, en Granada. Libro de Bautismos número 7, de enero de 1600 a mayo de 1610 . Índice y página 7. 
Un año después la pareja celebra en su parroquia otro bautismo (que aparece recogido en el mismo libro bautismal), el de una niña que recibe el nombre de Ana María. Junto a su nombre hay una indicación: «Ana María, sclava de Gabriel Mallén».

En seis días del mes de octubre de mil seiscientos y uno años bauticé a ana maría sclava de Gabriel Mallén. Fue su compadre el secretario Melchor de Adarve, testigos Juan Sillero y Bartolomé Muñoz. Era adulta. ${ }^{11}$

Los libros de bautismo de la Iglesia Sagrario-Catedral números 6, 7 y 8 han sido revisados página a página, buscando rastros de otros hijos de la pareja, pero Juan y Ana María son los únicos seres bautizados por Gabriel Mallén y su esposa en la parroquia. Ana María de Torres falleció no mucho tiempo después. Su entierro está registrado el 1 de octubre de 1606 también en la Iglesia Sagrario-Catedral, dentro de la que se enterró su cuerpo. «Ana María, de Gabriel Mallén, procurador de esta Real Audiencia. Enterrose en esta iglesia. No se dieron misas» ${ }^{12}$.

Cuando murió, Ana María de Torres tenía 31 años. Su marido, quedó viudo a los 37 años. Gabriel volvió a casarse y tuvo otro hijo. Contrajo matrimonio con Alfonsa de Loyola, natural de Granada. Se desconoce la fecha del enlace (un incendio que asoló el Archivo Histórico del Arzobispado de Granada destruyó numerosos documentos) y también la fecha exacta en la que nació el único hijo de ambos, pero debió ser alrededor de 1610. El niño fue preparado por sus padres para dedicar su vida a Dios como fraile dominico. Se formó como novicio en Granada, en el convento de Santa Cruz. En todas las informaciones documentales que hemos compilado sobre él aparece con el nombre de Fray Juan Mallén ${ }^{13}$. En 1637 estaba destinado en Manila, como lector en Teología.

Fue Vicario General de la provincia de Manila, dos veces Definidor en capítulos provinciales y por unos veinte años Predicador General, al mismo tiempo que ejercía otras funciones, tales como presidente del colegio de San Juan de Letrán y del hospital de San Gabriel de Binondo.

Falleció el 18 del 5 de 1663, en San Juan del Monte, siendo a la sazón vicario de aquella casa, predicador general y Comisario del Santo Oficio. Su cuerpo fue trasladado a Manila y sepultado en la iglesia del convento de Santo Domingo. (OCIO / NEIRA, 2000: 160-161)

En septiembre de 1643 el Comisario General de Manila, Fray Francisco Herrera, envía una carta a México y Madrid proponiendo que Fray Juan Mallén (junto a otro fraile dominico) sea nombrado Comisario del Santo Oficio, y solicitando que se inicien las gestiones oportunas para ese propósito, entre ellas demostrar la pureza de sangre del candidato y sus antepasados. La solicitud genera pesquisas por parte de la Inquisición, entre las que se encuentra realizar

11 Archivo parroquial de la iglesia de Sagrario-Catedral, en Granada. Libro de Bautismos número 7, de enero de 1600 a mayo de 1610 . Índice y página 76.

12 Archivo parroquial de la iglesia de Sagrario-Catedral, en Granada. Libro de Defunciones número 1, del 20 de noviembre de 1605 al 7 de marzo de 1617. (Este ejemplar fue originariamente el número 2, como el número 1 se extravió la numeración fue corregida a mano).

13 En nuestra investigación se realizaron visitas y se recabaron informaciones en diversos archivos de la Orden de los Predicadores (Padres Dominicos): el convento dominico de Santa Cruz de Granada, y el archivo general de la Cuarta Provincia Rosario-Filipinas, que esta orden trasladó desde Manila a Ávila (donde se encuentra en la actualidad). 
la «genealogía ascendente de Fray Juan Mallén». Esa documentación se guarda en el Archivo General de la Nación, de México.

Genealogía de Fray Juan Mallén, natural de Granada.

Su padre se llama Gabriel Caro de Mallén, natural de Sevilla, de Lora, a 9 leguas de Sevilla. Abuelos paternos Hernando Caro de Mallén y Catalina de Vargas, naturales de Sevilla.

Su madre se llama D. Alphonsa de Loyola, natural de Granada. Hija de Hernando de Párraga y D. Isabel de Loyola ${ }^{14}$.

Antes de abandonar España para trabajar como evangelizador en el Extremo Oriente, el joven estudiante Fray Juan Mallén culmina su formación religiosa en el sevillano convento de Santo Tomás de Sevilla, hoy desaparecido. Con ese propósito, alrededor de 1625, los Caro de Mallén se trasladan desde Granada a Sevilla, ciudad en la que se quedan a vivir. En el grupo van Gabriel y su esposa Alfonsa, en compañía de Ana María y el joven aspirante a dominico. El hijo mayor no les acompaña. En aquella época, Juan Caro de Mallén ya había formado su propia familia. Juan Caro de Mallén de Torres se casó con Lucía de Azpeitia en la granadina parroquia de Santos Justo y Pastor. El certificado de matrimonio tiene fecha del 28 de marzo de 1617. El novio asegura tener dieciséis años de edad y realiza una insólita petición, pide permiso a las autoridades para casarse con su novia, «ya que siendo mis padres ricos y ella pobre, es lógico que se opongan ${ }^{15}$. El novio estaba realizando un enlace a espaldas de su familia, con una joven mayor que él. De ese matrimonio nacería Sancho Caro de Mallén.

Pero Juan, igual que su padre, enviudó joven, y volvió a casarse con doña Luisa de Ávila, con quien no tuvo descendencia. En la década de 1630 terminó por instalarse en Madrid, ciudad en la que acabaría sus días. En Madrid estuvo vinculado a la Corte y a Felipe IV. Fue caballerizo mayor de doña Elvira Ponce de León (Marquesa de Villanueva de Valdueza y Camarera mayor de la Reina) cargo que implicaba tareas de administración de bienes. El Archivo Histórico Nacional y la Biblioteca Nacional de España guardan documentos sobre su quehacer profesional. Uno de ellos es un documento fechado en 1649 y dirigido directamente a Felipe IV en el que se demuestra hasta qué punto su persona y opinión tenían influencia en el monarca (y confianza para hacerle recomendaciones) ya que le da consejos para mejorar el estado de la hacienda pública con medidas tales como evitar los abusos de ministros y otros intermediarios:

Señor: Don Juan Caro de Mallén, vezino de la ciudad de Granada, residente en esta Corte, con el celo que siempre ha mostrado al servicio de v. M. y del aliuio de estos reinos, hauiendo reconocido los muy graves daños que se an causado con la rigurosa administración de los seruicios de millones y sus ministros y los fraudes tan grandes que an ocasionado lo crecido de los tributos y los que an procedido

14 Carta de Comisario de Manila, Francisco de Herrera, proponiendo para Comisario a Fray Francisco de Paula y Fray Juan Mallén: sus genealogías. Archivo General de la Nación. México DF. Instituciones Coloniales, Inquisición (61)/Volumen 416, expediente 2, Año de 1642. Hojas 6 a 13.

15 El expediente matrimonial de Juan Caro de Mallén y Lucía de Azpeitia se encuentra en el Archivo Histórico del Arzobispado de Granada. Legajo 70, pieza n ${ }^{\circ}$ 108. La inscripción de la boda se encuentra en el Archivo Parroquial de la Iglesia de Santos Justo y Pastor, de Granada, Libro de Desposorios y Velaciones de octubre de 1616 a septiembre de 1653, índice (letra J) y página 3v. En ese documento, como en el anterior, la novia aparece con el apellido de la madre (viuda) Azpeitia. Su madre era Isabel de Azpeitia, su padre Domingo de Arriola. 
del subido de la sal y el papel sellado y los excesiuos y grandes gastos que an sobrevenido a esta monarquía con las guerras y demás accidentes que se an ofrecido, propone a v. M. el remedio siguiente ${ }^{16}$.

En este documento, Juan menciona a varios testigos de Sevilla capital (por ejemplo Manuel Fernández de Miranda) que aportan su testimonio sobre los abusos y malas prácticas que los administradores públicos realizan. Sus conocimientos acerca de personas y hechos concretos de Sevilla, que acompaña de todo lujo de detalles y cifras, dejan entrever su estrecha relación con la ciudad en la que residía su familia. Las informaciones del documento son relativas al año 1645 y siguientes (hasta 1648).

En el año 1617, en Granada, mientras Juan Caro de Mallén concierta su boda a espaldas de su familia, su padre Gabriel todavía ejerce como procurador en la Real Audiencia y Chancillería. Su nombre aparece en un documento oficial, la petición de una ejecutoria de hidalguía solicitada por don Andrés criado de Castilla. Gabriel Caro de Mallén realiza el doble papel de procurador y representante del peticionario. En la Executoria, que terminó en un anticuario de Granada que la vendió a la Diputación de Jaén (que hoy custodia el documento), se refleja la larga comparecencia que el procurador de la Real Audiencia de Granada «Gabriel Mallén» realizó ante «los alcaldes de los hijosdalgo». La fecha de su comparecencia fue el 23 de septiembre de 1616. El proceso, con fallo favorable para el peticionario, finalizó en $1618^{17}$.

Siete años más tarde, la familia estaría instalada en Sevilla, ciudad en la que Ana María Caro de Mallén de Torres inicia su carrera literaria y en la que en 1628 publica el primer texto que conservamos de ella.

\section{ANA MARÍA Y SU ENTORNO FAMILIAR}

El segundo nombre de Ana Caro Mallén (María) solo es utilizado por la escritora una vez a lo largo de toda su producción literaria, en un poema laudatorio que dedica a María de Zayas (para la edición de sus Novelas Amorosas y Exemplares de 1638). En esa ocasión firma como María Caro de Mallén, hecho que hasta la fecha había desatado especulaciones tales como que se hubiera podido producir algún error por parte del editor al trascribir su nombre. Con los hallazgos documentales mencionados en este trabajo se comprueba que no existe error, sencillamente, los Caro de Mallén quisieron que el nombre de su hija adoptiva fuera el mismo que el de la madre de la familia, Ana María.

La adopción ya era una institución plenamente desarrollada en el antiguo derecho romano. De él la recibe en el siglo XIII el Código de las Siete Partidas de Alfonso X el Sabio, vigente en España durante siglos, y donde el prohijamiento (traducción castellana de la adopción) está tratado en la partida cuarta.

Porfijados son una manera de fijos, a que dizen en latin, adoptivi, a quien reciben los omes por fijos; maguer non nacen ellos de casamiento, nin de otra guisa. Onde, pues que en los Títulos ante deste fablamos de los fijos legitimos, e todos los otros que han los omes natu-

${ }^{16}$ Memorial que D. Juan Caro de Mallén dio a S.M., en el que le propone algunos planes para mejorar la Hacienda Pública. Fechado en 1649. Biblioteca Nacional de España. Mss: 18.654. (Signatura antigua Folio C-25, num. 14.)

17 Executoria de Hidalguía obtenida por Don Alonso Criado de Castilla y su hijo Don Andrés. Año 1618. Texto Original. Biblioteca de Estudios Giennenses. Caja 4.604, pieza 7. 
ralmente; queremos aquí decir destos, que ganan por postura que fazen entre si, segun ley, e fuero. (Partida Cuarta, Título XVI, Preámbulo)

No todo el mundo podía «prohijar». Se exigía que lo hiciera una persona libre, emancipada de la tutela paterna, que fuera varón con demostrada capacidad natural para engendrar por él mismo y que tuviera como mínimo dieciocho años más que el prohijado. Los prohijados podían adquirir derechos de todo tipo, incluso hereditarios, y el adoptante recibía la patria potestad. (Iglesias Rodríguez, 2011: 114)

¿Qué significaba en aquel contexto histórico que Ana María fuera esclava y la coletilla «era adulta» que aparece al final de su inscripción bautismal? España fue el último país occidental en abolir la esclavitud, fenómeno que Granada padeció especialmente en el tránsito del siglo xvI al XVII, debido a la rebelión de los moriscos de finales del siglo XVI. El profesor Francisco SánchezMontes, especialista en Historia Moderna y uno de los pioneros en la investigación de la esclavitud en Granada, cuenta en su libro La población granadina en el siglo XVII, que los sublevados, mudéjares conversos al cristianismo o descendientes de ellos, protagonizaron una revuelva que vivió su momento álgido entre 1568 y 1571, y que terminó con su derrota. Desde finales del siglo xVI hasta 1609, en el que se decreta la expulsión definitiva de los moriscos de España (expulsión que finalizaría en 1614), esta población es dispersada para evitar nuevos levantamientos. Muchos son ejecutados (incluidas mujeres), otros apresados y enviados a galeras, y familias enteras son separadas, vendiéndose a los niños y niñas como esclavos para que fueran cristianizados por sus compradores. Esta población no se distinguía por sus rasgos exteriores, como sí ocurría con los esclavos africanos que entraban desde el puerto de Sevilla; algunos eran árabes, pero otros incluso castellanos. El término morisco (o mudéjar) no estaba vinculado a una raza o color de piel, sino a creencias religiosas. (Martín Casares, 2010)

En el Archivo General de Simancas existen documentos en los que el rey Felipe II consulta qué hacer con estos moriscos sometidos ${ }^{18}$. El Consejo de Castilla, el Arzobispado de Granada y otras entidades dan su opinión. Para ejecutar los castigos la mayoría de edad penal ese sitúa para los varones en los diez años y medio, y para las mujeres en los nueve años y medio. En los documentos se habla de «hombres» de 10 años y medio $\mathrm{y}$ «mujeres» de nueve años y medio, edad a la que ya entraban en la categoría de adultos. La existencia de numerosas recomendaciones acerca de cómo actuar con los vencidos (que a veces se contradicen entre sí y en otras ocasiones son reiterativas y recuerdan que hay que cumplir con lo que ya se ha establecido) dibujan el marco de confusión, atropellos y diferencias de trato que unos y otros moriscos padecieran, en función de dónde fueran apresados y por qué autoridad.

Para acabar de complicar el panorama, en un momento dado Felipe II se percata de que su decisión de esclavizar a seres humanos que eran cristianos puede generarle oposiciones entre la propia cristiandad (los moriscos o mudéjares eran antiguos practicantes de la religión islámica convertidos al cristianismo), e incluso la oposición del Papa de Roma, «y en contra de la necesaria publicidad que una pragmática exigía, decidió que la resolución legal que se tomara respecto a ellos solo debería comunicarse a los directamente encargados de su aplicación: la Audiencia de Granada» (Benítez Sánchez-Blanco, 2010: 30).

18 Archivo General de Simancas, Cámara de Castilla, legajo 2152, hoja n. 265. 
Durante generaciones, se cometieron abusos de todo tipo, fundamentalmente en el caso de los niños esclavizados. Luis del Mármol, uno de los militares directamente encargados de sofocar la revuelta, escribe en su crónica de primera mano sobre estos acontecimientos que los abusos con los niños provocaron que se publicara un bando en el que se exigía que estos fueran entregados a cristianos viejos para su custodia y administración (Del Mármol, 1600). En las sucesivas y desordenadas expulsiones de moriscos producidas antes de la gran expulsión de 1609, los adultos quedaban libres para marcharse, pero dada su dificultad para expulsar a los niños pequeños, se decide que lo mejor es esclavizarles por su propio bien espiritual. (Sánchez-Blanco, 2010: 41). El hecho de ser menor había acabado por convertirse en una desventaja.

En la Edad Moderna se produce una exaltación del prohijamiento como acto virtuoso que acerca a los cristianos a Dios. (Iglesias Rodríguez, 2011: 127) Esta exaltación y expansión del prohijamiento fue fomentada en gran medida por la Corona para dar solución a parte de este conflicto social. «El Rey, fomenta que los niños moriscos sean acogidos en familias de cristianos viejos. A finales del siglo XV se consolida la doctrina a favor del trato humanitario con estos niños. El objetivo de la Corona era integrarlos» (Pérez García / Fernández Chaves, 2011: 163)

Gabriel Caro de Mallén era procurador de la Real Audiencia de Granada, a la que llegaban las noticias sobre la existencia de estos cautivos y se decidía sobre su futuro. Los hijos de estos detenidos, nacían esclavos (Periañez Gómez, 2011: 190). Nunca podremos saber si la niña a la que bautizó con el nombre de su mujer llegó directamente a sus manos o era hija biológica de alguna esclava morisca que servía a la familia y que tal vez falleció, pero su acción al bautizarla fue un acto de acogimiento y protección hacia la niña. El párroco de la Iglesia Sagrario-Catedral y responsable del archivo documental de la misma, D. Carlos del Castillo Jiménez, y otros expertos en inscripciones bautismales de la época a quienes se consultó el documento (entre ellos la responsable del Archivo Histórico de la Curia de Granada, Inmaculada Bertos) encuentran en él varios datos que corroboran el acto de «prohijamiento», la aparición de la figura del «compadre», como elemento de padrinazgo, y el hecho de que los padres biológicos de la recién nacida no sean mencionados.

¿Qué significaba en el caso de Ana María «Era adulta»? ¿Podemos saber la edad exacta que tenía cuando fue bautizada? Teniendo en cuenta la «edad penal» establecida en la época para los esclavos, podía tratarse de una niña cercana a los diez años. En la parroquia de la localidad granadina de Íllora, el investigador Antonio Verdejo Martín (alumno del profesor Francisco Sánchez-Montes y como él estudioso de la historia de la esclavitud en Granada) menciona una inscripción de bautismo de 1618 de una esclava «ysabel, adulta de edad de diez años». En el cálculo hay que tener en cuenta otro factor ya mencionado, la ley obligaba a que quien prohijaba tuviera, como mínimo, dieciocho años más que su prohijado. Por otro lado, la obligación de quien prohijaba de demostrar que podía tener hijos biológicos, puede interpretarse como que Ana María vivía bajo aquel techo hacía años, y hubo que esperar a que naciera su hermano Juan para consumar la legalidad de su situación.

La historia de Ana María Caro de Mallén hace patente el verdadero grado de complejidad de la España del Siglo de Oro. También en Granada encontramos al antiguo esclavo de origen africano Juan Latino, vendido a los Duques de Sesa, quienes admirados por sus dotes artísticas e inteligencia, le educaron junto a su hijo, asistiendo a clases 
en la Universidad de Granada. Juan Latino (Juan de Sesa) terminó por obtener la libertad y una cátedra de Gramática y Lengua Latina, en la que desempeñó tareas docentes durante veinte años. La biografía de este personaje se encuentra en numerosas publicaciones. Henríquez de la Jorquera hace referencia a su muerte, acaecida en 1590.

Domingo doce días deste mes de agosto de mil y quinientos y noventa, falleció en esta ciudad de Granada el maestro Juan Latino, de color negro, uno de los más eminentes negros que se han conocido en el mundo, catedrático que fue muchos años en el real Colejio y universidad desta dicha ciudad cuya fama será celebrada para siempre. Criose en las casas de los Duques de Sesa, a donde nació debaxo de cautiverio, de quien hizo grande estimación y aprecio el duque (...)

Escribió algunos libros gramáticos y el famoso libro que intituló la austriada de Carlos V y otros. (Henríquez de la Jorquera, 1934: 533)

\section{Ana María Caro de Mallén: trayectoria Vital y literaria}

La extraordinaria cultura que poseía Ana María Caro de Mallén y la sólida educación que debió recibir por parte de sus progenitores se manifiesta en todas sus creaciones. Sus referencias mitológicas e históricas y su dominio de los clásicos permiten adivinar largos años de estudio y preparación. Sus conocimientos sobre sus contemporáneos definen una mente intelectualmente inquieta y en continua formación. Era una mujer interesada por el presente, por los acontecimientos sociales y políticos que la rodeaban: brillante y con capacidad de análisis. Su discurso era el del poder, el de la clase social que la había admitido y conformado como ser humano, pero la ironía y la crítica nunca faltan en sus páginas, dejando entrever sus progresistas ideas sobre la vida y el mundo. La delicadeza con la que caracteriza en sus obras teatrales a los criados y personajes más humildes (humillados y vapuleados) y el continuo deseo de estos de saltarse las normas sociales para demostrar su verdadera valía, muestran su mentalidad.

Que su producción literaria fue más extensa que los pocos testimonios que han llegado hasta nosotros es fácil de deducir, se adivina mucha práctica tras su nivel creativo. Su notorio dominio de la técnica de la versificación es innegable, igual que su pericia para la construcción dramática: las dos comedias que conocemos de ella son evidentemente obras de madurez. Otros hechos avalan una perdida producción literaria de esta autora, fundamentalmente los testimonios de sus contemporáneos acerca de su extensa obra. En ese sentido, nuestra investigación ha encontrado un documento inédito que apoya esta teoría, una referencia en las actas capitulares del Cabildo de Sevilla del 14 de junio de 1641 en el que la autora reclama el pago por un auto sacramental cuyo título no se menciona. El nombre de Ana Caro Mallén aparece junto al de tres autores que también demandan el pago por sus obras: Fernando de la Torre ${ }^{19}$, Cristóbal de Mora y Antonio de Torquemada.

y en el caso de don fernando de la torre, don cristobal de mora, doña ana Caro mallén y don antonio de Torquemada, vecinos de esta ciudad, en que dicen que ellos escribieron los autos que se representaron en las fiestas del santísimo sacramento de este año, y porque no se les ha dado la satisfascion de sus trabajos = dicen a la ciudad se sirva de que se les pague

19 De entre todos los autores mencionados, destaca Fernando de la Torre Farfán (1609-1677), sacerdote, cronista, poeta y traductor sevillano, que también ha pasado a la historia como animador de justas literarias. Algunas de las obras de este autor todavía pueden encontrarse en el mercado editorial. 
la cantidad que otros años se suele dar. (Archivo Municipal de Sevilla. Actas Capitulares. Primera Escribanía, 14 de junio de 1641. Signatura: H/1651

Una vez abandonó Granada, Ana María Caro de Mallén pasó toda su vida en Sevilla. En esa ciudad, en la que inició y desarrolló su carrera literaria, vivió sin interrupción con la única excepción del viaje que realizó a Madrid en 1937, requerida desde la Corte para escribir la relación de una boda real ${ }^{20}$. En Sevilla perteneció a la academia literaria que sostenía el conde de la Torre y recibió la protección de numerosas personalidades. Su familia fue una referencia continua para ella: su viaje a Madrid para realizar un trabajo por encargo coincide con la época en la que su hermano mayor aconseja al Rey y es protegido del poderoso Conde Duque de Olivares (a quien la propia Ana María escribe cartas y dedica su relación); en su comedia Valor, agravio y mujer el hermano de la protagonista sirve en la corte como caballerizo mayor (como lo hacía su hermano Juan) y esta emplea el apellido Ponce de León (el de la marquesa y camarera de la Reina a quien sirve Juan). Su hermano menor, Fray Juan Mallén, también está presente en sus escritos: la relación que Ana María realiza en 1628 como homenaje a los mártires del Japón describe un suceso que influía directamente en Fray Juan, que se preparaba para ser misionero en el Extremo Oriente. Los Dominicos, (junto a franciscanos y jesuitas) realizaban labores de evangelización en ese territorio, considerado por la orden de los Dominicos como la «Cuarta Provincia: Rosario-Filipinas», con sede en Manila, donde Fray Juan Mallén desarrolló toda su carrera.

Ana María Caro de Mallén alcanzó fama en su época, tuvo acceso al mundo editorial y publicó y reeditó sus textos dramáticos en solitario y en antologías en las que fue acompañada de escritores de primera talla. Valor, agravio y mujer aparece en compendios de comedias junto a obras de Lope de Vega, Calderón de la Barca, Diego de Torres y Villarroel, Gerónimo de Cifuentes, Carlos de Arellano o sor Juana Inés de la Cruz. El conde Partinuplés se publicó en Laurel de Comedias. La nómina de dramaturgos que la acompañaban en aquella ocasión eran: Pedro Calderón de la Barca, Francisco de Vitoria, Luis Vélez de Guevara, Juan Ruiz de Alarcón, Antonio de Mendoza, Antonio Mira de Amescua, Gaspar de Ávila...

De toda la producción literaria de esta autora, solamente han llegado hasta nosotros dos comedias, una loa, un coloquio sacramental, cuatro relaciones y cinco poemas sueltos. En 1645 escribe y cobra en Sevilla la última pieza teatral que conocemos y conservamos de ella. Ese mismo año aparece impreso un soneto dedicado al notario Tomás de Palomares (Marinero feliz que nunca hallamos...) que se publica en la obra Estilo nuevo de escrituras públicas, del mencionado notario. En 1646 encontramos la última de sus creaciones, un soneto para doña Inés Jacinta Manrique de Lara (Si pensara, señora, que al terrible...) compilado en el manuscrito Sonetos varios recogidos aquí de diferentes autores assi de manuscriptos como de algunos impressos. «Por don Joseph Maldonado

20 Las «relaciones» son un género antecesor del periodismo que cobró auge durante el Siglo de Oro. Se escribían en verso, convirtiéndose en la crónica poética de un suceso. Se imprimía en pliegos sueltos, y posteriormente eran divulgadas masivamente. El «relacionero» más famoso de la época fue Andrés de Almansa y Mendoza. Francisco Gutiérrez Carbajo contextualiza la vida y obra de este personaje, aportando valiosas referencias sobre este género antecesor del periodismo, en su artículo Los comienzos del periodismo: Diario ABC, año 2002, suplemento El Cultural, pp. 16. 
Davila y Saavedra, vesino de Sevilla, año de 1646» (folios 82v y 83r) A partir de ahí la pista de la autora se pierde para siempre.

Hemos encontrado en Sevilla una inscripción de fallecimiento del seis de noviembre de 1646 a nombre de doña María Ana Caro (que nuestra investigación atribuye a la autora $^{21}$ ). La inscripción ha sido hallada en la Real Parroquia de Santa María Magdalena, que se encuentra ubicada dentro del edificio que fue el Convento de San Pablo el Real. Este convento, del que los frailes dominicos fueron expulsados en el siglo XIX durante la «desamortización de Mendizábal», era en vida de Ana María Caro de Mallén la casa madre de la orden de los Frailes Dominicos para Andalucía y los territorios de América. En su fachada, una placa recuerda que en aquel recinto, el sevillano Fray Bartolomé de las Casas fue consagrado obispo de Chiapas el 30 de marzo de 1544. Durante el siglo XVII, el edificio fue al mismo tiempo que convento dominico, Sede de la Inquisición, en la que su hermano Fray Juan Mallén, ostentó el cargo de comisario. Desde él, se organizaban los viajes de los frailes predicadores a Extremo Oriente, con escala obligatoria en México, ciudad en la que se guardaba la genealogía ascendente de este personaje.

La inscripción del fallecimiento dice: «en ese día, doña marí ana Caro en la Rabeta. $12344^{22}$. Los números que acompañan a la inscripción se corresponden con el montante económico recibido por la iglesia para organizar el acto de enterramiento de la finada. El entierro de «doña marí ana Caro» es uno de los más costosos celebrado en esas fechas. Se contabilizan por ella, en reales de la época, los siguientes gastos: «Sepultura 12. Capas 3. Dobles 4. Ciriales 4.» Los conceptos de los gastos hacen referencia al ornato de su sepultura, a los religiosos con capa que escoltaron el cortejo («capas»), a los dobles de campana con los que se anunció su fallecimiento («dobles») y a los portadores de cirios que se unieron a la comitiva («ciriales»).

D. Antonio Fernández Estévez, actualmente párroco de esta iglesia, constata que la inscripción se encuentra dentro de un listado de fallecidos por la peste, caracterizados porque son una simple lista de nombres a la que se adjunta el lugar del fallecimiento, sin añadir más datos sobre las circunstancias del mismo. Todo apunta a que Ana María Caro de Mallén falleció a causa de esa epidemia en «La Rabeta», nombre de una plaza de la Sevilla del siglo XVII. En aquel lugar hubo en la antigüedad un hospital, que se conocía por la misma denominación que la plaza. En el plano de Sevilla de Olavide de 1771 aún aparece la plaza de La Rabeta», que hoy se denomina «Plaza de Godines». Un azulejo recuerda todavía el antiguo nombre del enclave, próximo a la Real Parroquia de Santa María Magdalena, en cuyas inmediaciones debió residir la autora.

Las circunstancias de su fallecimiento refuerzan la teoría de que Ana María Caro Mallén de Torres escribió una obra más extensa de la que conocemos y ha llegado hasta nosotros. El destino de su legado, de toda aquella producción que no pudo editar o hacer pasar a la posteridad en forma manuscrita, debió ser el que en la época se tributaba a las pertenencias de los fallecidos por la epidemia de la peste: el fuego.

21 Para esta atribución se ha realizado un cotejo con los libros de defunciones de las parroquias existentes en Sevilla en aquella época, desde la fecha de la última información documentada que poseemos sobre Ana María Caro de Mallén (1646-enero) hasta diez años después (1656), no habiéndose encontrado ninguna Ana Caro o similar.

22 Archivo Parroquial de la Real Parroquia de Santa María Magdalena. Libro $2^{\circ}$ de entierros, desde 1624 a 1669. Página 36r. 


\section{REFERENCIAS BIBLIOGRÁFICAS}

Benítez Sánchez Blanco, Rafael. (2010) El cautiverio de los moriscos. Manuscrits no 28. Barcelona: Revista de Historia Moderna de la Universidad Autónoma de Barcelona, pp. 19-43.

Cuartero Huerta, Baltasar y Marqués de Siete Iglesias. (1949-1979) Índice de la Colección de don Luis de Salazar y Castro. Madrid: Real Academia de la Historia, 49 vols.

Delgado, María José. (1993) Valor, agravio y mujer y El conde Partinuplés, de Ana Caro: una edición crítica. Tesis. Arizona: Universidad de Arizona.

Foley, Luisa. (1977) Valor, agravio y mujer, by Doña Ana Caro Mallén de Soto. Annotated Critical Edition with Introductory Critical Study. Master's Tesis. (mecanograf. 86 pp) Temple: Temple University.

García Carraffa, Alberto y Arturo. (1920-1963) Diccionario Heráldico y Genealógico de Apellidos Españoles y Americanos. Madrid: Imprenta Antonio Marzo, 86 vols.

González Carballo, José. (1987) Documentación inédita hallada recientemente en el archivo municipal de Lora del Río. Estudios sobre Lora en la primera mitad del siglo XVI. Biblioteca de temas loreños. Lora del Río: Agrupación cultural amigos de Lora y Delegación de cultura del Ayuntamiento de Lora.

Gutiérrez Carbajo, Francisco. (2002) «Los comienzos del periodismo». Diario ABC, (Suplemento ABC Cultural) 16-03-2002. pp.16.

Henríquez de la Jorquera, Francisco. (1934) Anales de Granada. Vols. I y II. Edición preparada según el manuscrito original por Antonio Marín Ocete. Granada: Publicaciones de la Facultad de Letras.

IgLesias Rodríguez, Juan José. (2011) «El prohijamiento o adopción en la Edad Moderna: Ley, práctica y doctrina», en La infancia en España y Portugal. Siglos XVI-XIX, Francisco Núñez Roldán (ed.) Madrid: Sílex, pp. 111-131.

LunA, Lola. (1993) Valor, agravio y mujer, de Ana Caro. Madrid: Castalia.

Mármol, Luis del. (1797) Historia de la rebelión y el castigo de los moriscos del Reyno de Granada. Madrid: Imprenta de Sancha, MDCCXCVII.

Martín Casares, Aurelia. (2010) La esclavitud en la historia de España. Siglos XVI y XVII. Granada: Editorial Colmares.

Mena, Sebastián de (compilador) (1601) Ordenanzas de la Real Audiencia y Chancillería de Granada. Granada: edición de Sebastián de Mena.

Ocio, Hilario / NeIRA, Eladio. (2000) Misioneros Dominicos en el Extremo Oriente: 1587-1835. Manila: Orientalia Dominicana.

Pérez García, Rafael M. / Fernández Chaves, Manuel. (2011) «La infancia morisca, entre la educación y la explotación», en La infancia en España y Portugal. Siglos XVI-XIX, Francisco Núñez Roldán (ed.) Madrid, Sílex, pp. 149-186.

Pérez Pastor, Cristóbal. (1911) Noticias y documentos. En Memorias de la Real Academia Española. Tomo X. Madrid: RAE.

Periáñez Gómez, Rocío. (2011) «La esclavitud infantil en la España Moderna» en La infancia en España y Portugal. Siglos XVI-XIX, Francisco Núñez Roldán (ed.) Madrid: Sílex, pp. 187-202.

Salazar Mir, Adolfo de. (1995-1996) Los expedientes de limpieza de sangre de la catedral de Sevilla (genealogías), tres vols. Madrid: Instituto Salazar y Castro.

SÁnchez ArJona, José. (1889) Noticias referentes a los Anales del Teatro en Sevilla: desde Lope de Rueda hasta finales del siglo XVII. Sevilla: Imprenta de E. Rasco.

SÁnchez-Montes González, Francisco. La población granadina en el siglo XVII. Granada, Universidad de Granada-Ayuntamiento de Granada, 1989.

SÁnchez Saus, Rafael. (1991) Linajes sevillanos medievales, dos vols. Sevilla: Ediciones Guadalquivir. 
Sentaurens, Jean. (1984) Seville et le theatre. De la fin du moyen age a fin du XVIII siècle. Talence: Presses Universitaires de Bordeaux, pp. 1119-1149.

Serrano y Sanz, Manuel. (1903) Apuntes para una Biblioteca de Escritoras Españolas desde el año 1401 al 1833. Madrid: Rivadeneira. (Edición facsímil, Madrid, Atlas, 1975.)

Soufas, Teresa Scott. (1991) Ana Caro's Re-evaluation of the Mujer varonil and Her Theatrics in Valor, agravio y mujer, in The Perception of Women in Spanish Theater of the Golden Age. Anita K. Stoll and Dawn L. Smith (eds.) Lewisburg: Bucknell University Press / London: Associated University Press, pp. 291-303.

Stroud, Matthew. (1986) La literatura y la mujer en el Barroco. Valor, agravio y mujer, de Ana Caro. Actas del VIII Congreso de la Asociación Internacional de Hispanistas. Stroud, Mathew. D. Kossoff, J. Amor y Vázquez, G. Ribgans y R. Kossof, (eds.) Madrid: Editorial ISTMO, pp. 605-612. 